\title{
Assessing technological feasibility for wastewater reclamation based on early life stage toxicity of Japanese medaka (Oryzias latipes)
}

\author{
Jinmiao Zha, Zijian Wang* \\ State Key Laboratory of Environmental Aquatic Chemistry, Research Center for Eco-Environmental Sciences, \\ Chinese Academy of Sciences, P.O. Box 2871, Shuangqing Rd. 18, Haidian District, Beijing 100085, PR China
}

Received 31 December 2003; received in revised form 21 October 2004; accepted 29 November 2004

\begin{abstract}
To assess technological feasibility for reuse of secondary effluent from sewage treatment plant, the effects of raw sewage (RW) water sample and effluents samples from secondary treatment (SS), ultrafiltration treatment after SS (SS-UF), microfiltration treatment after SS (SS-MF), activated carbon column adsorption after SS (SS-AC), as well as reverse osmosis treatment after SS-UF (SS-UF-RO) were assessed using embryo larval development of Japanese medaka (Oryzias latipes). Samples of RW and effluents from secondary treatment were taken from Beixiaohe sewage treatment plant (STP) in Beijing, China. Newly fertilized embryos ( $<5$-h-old) were exposed to these water samples at different concentration gradients (including 100, 50, 25, $12.5,6.25 \%$ effluent concentrations) in a 24-h static renewal system at $25 \pm 1{ }^{\circ} \mathrm{C}$ for 15 day post-hatch. The assay considered both acute toxicity using endpoint of 96-h larval morality and chronic toxicity using endpoints including the time to hatch, hatching success, deformity, growth rate, swim-up failure, accumulative mortality and sex ratio. In the 96-h larval mortality test, 96h LC50 for RW, and effluents from SS, SS-UF and SS-MF on medaka larval were 33.7, 62.9, 60.0, 64.4\% concentrations, respectively. However, no acute toxicity was observed for effluents from SS-AC and SS-UF-RO. No embryos exposed to $100 \%$ RW effluent hatched. Most of the endpoints were alternated when the fish was exposed to effluents from SS, RW, SS-UF, SS-MF that were 50-100\% concentration, except those of growth and time to hatch $(P<0.05)$. The sex ratio of the larvae was alternated when exposed to 25\% effluents from RW and 50\% effluents from SS, SS-UF and SS-MF. Sex ratios in treatments with effluents from SS-AC and SS-UF-RO were not significantly different with the controls. However, embryos lesions and swim-up failure were still significantly different from the controls for $100 \%$ effluent from SS-AC $(P<0.05)$ and swim-up failure and larval growth could be observed for 100\% effluent from SS-UF-RO $(P<0.05)$. We conclude that acute toxicity was present in the sewage water and secondary treatment could remove only part of the toxicants. As advanced treatment technologies, membrane technologies could not further remove trace toxicants and endocrine disruptors. Activated carbon adsorption and reverse osmosis were effective in removing most of the toxicants, but discharge without dilution could still manifest potential ecological risk on
\end{abstract}

\footnotetext{
* Corresponding author. Tel.: +86 106284 9140; fax: +86 1062923543.

E-mail address: wangzj@mail.rcees.ac.cn (Z. Wang).
} 
receiving aquatic biology. We conclude that activated carbon adsorption and reverse osmosis are relatively feasible technologies for reuse of secondary effluents from sewage treatment plant.

(C) 2004 Elsevier B.V. All rights reserved.

Keywords: Advanced treatment technologies; Secondary effluents; Toxicity; Bioassay; Japanese medaka (Oryzias latipes)

\section{Introduction}

Most of the sewage treatment plants (STPs) in China receive complex mixtures of urban and industrialized discharges. Even after secondary treatment, they still contain a vast number of diverse chemical substances, many of which are unknown, to the receiving water (Trevizo and Nirmalak, 1999). When the effluents are recycled for certain purposes such as irrigation, advanced treatment is generally required. Advanced treatment technologies for reclamation of effluents from sewage treatment plants have increased rapidly in recent years in China. Currently the available technologies mainly include membrane filtration, activated carbon absorption, chemical oxidation and combinational biological treatment. Previous work has demonstrated that different technologies have different features regarding the target pollutants. For example, membrane filtration has high virus removal efficiency and was increasingly applied in disinfection processes for raw water and municipal effluent reuse (Madaeni et al., 1995; Glucina et al., 2000; Mousa et al., 2003). Activated carbon is effective in the adsorbent removal of volatile organic compounds in sewage treatment (Bansode et al., 2003). With the wrong selection, some treatment technologies may result in the discharges of toxic chemicals and pathogenic microorganisms (Chaler et al., 2001). Therefore, the effluent should be evaluated depending on the intended application.

Difference of the effluent from various stages of treatment has traditionally been regulated using methods with unspecified responses and by measuring global parameters, such as the dissolved organic content (DOC) or the chemical oxygen demand (COD). Moreover, the effects of effluents are largely unknown and the ecological hazards of effluent reuse are still very lacking. The characteristics of different secondary effluents vary with categories and the effluent guideline for different categories needs to be identified independently. For example, a previous study has demonstrated that effluents from sewage treatment plants (STPs) had effects on fish at cellular, organ, organism and community levels (Clint et al., 2003). In addition, some secondary effluents have been found to be estrogenic to juvenile fish (McArdle et al., 2000; Julia et al., 2002), while no significant effects were observed in maturing rainbow trout exposed to effluent of a pulp and paper mill (Heuvel et al., 2002). In recent years, some studies have shown the removal of endocrine disruptors from treated effluent using yeast estrogen screen and the ethoxy resorufin- $O$-deethylase (EROD) induction assay (Anders et al., 2003; Chunxia et al., 2003). Currently there is little work being carried out to determine the differences of effluents from various treatment technologies, especially membrane treatment technologies.

In recent whole effluent toxicity (WET) tests for short-term chronic toxicity, adverse effects were assayed using embryo-larval survival and teratogenicity of fathead minnow (Pimephales promelas) test method (USEPA, 2002). However, this test method is based on the total frequency of mortalities and gross morphological deformities. Many field studies suggest effects on fish in polluted habitats, including reduced reproduction success (Petersen et al., 1997), reduced the levels of plasma estrogens in males (Johnson et al., 1988) and alternation in sex ratio (Lang et al., 1995). In addition, M74 syndrome and early mortality syndrome (EMS) were observed in fry and embryo. Some studies have reported that effluent from sewage treatment plants have both teratogenicity and estrogenic activity (Fuerchker et al., 2001; Montsrrat et al., 2001). Estrogenic activity was not been included in the recent WET.

Medaka (Oryzias latipes) serves as an excellent fish model to determine acute and chronic toxicities, including the endocrine disrupting activity of chemicals. Many reports have suggested that medaka is sensitive to toxicants and endocrine disrupting chemicals (Scholz and Gutzeit, 2000; Metcalfe et al., 2001; Islinger et al., 2002), especially in early 
life stage. In the present study, to assess technological feasibility for reuse of secondary effluent from sewage treatment plant, toxicity of effluents from various processes (i.e. treatment technologies) on medaka $(O$. latipes) was assessed based on a variety of endpoints including lethal, sub-lethal, growth, deformities and sexual ratio. The effects of the effluents are discussed in relation to the hazardous risk that they put into the ecological system.

\section{Materials and methods}

\subsection{Sampling and processing}

All effluent samples were taken from Beixiaohe STP in Beijing. Effluents samples were taken from the in situ pilot advanced treatment setups, including those from secondary treatment (SS), ultrafiltration treatment after SS (SS-UF), micro-filtration treatment after SS (SS-MF), active carbon column adsorption after SS (SS-AC), as well as reverse osmosis treatment after SS-UF (SS-US-RO) expect raw sewage water (RW). All effluents samples were outflow from the various stages of treatment including listed above. Samples of technical details of the treatment technologies will be described elsewhere (Zha and Wang, in preparation).

The effluent samples were collected over a 24-h period according to composite sampling methods (USEPA, 2002) and delivered to the laboratory at 0 $6{ }^{\circ} \mathrm{C}$ within a few hours. Water quality parameters including $\mathrm{pH}$, dissolved oxygen (DO), total dissolved solids (TDS) and conductivity (CON) were determined using a portable multi-parameter meter (HACH, USA) immediately after the effluent samples were carried to the laboratory. The effluents were filtered through $60-\mu \mathrm{m}$ plankton net to remove indigenous organisms and the frozen. Prior to use, the effluents were then thawed.

\subsection{Test fish}

Japanese medaka (d-rR) was kindly provided by the Laboratory of Freshwater Fish Stock in Bioscience Center, Nagoya University, Japan. The brood stock was kept in dechlorinated tap water (using active carbon column $)$ at a constant temperature $\left(25 \pm 2{ }^{\circ} \mathrm{C}\right)$ with a photoperiod of $16: 8 \mathrm{~h}$ (light:dark). The brood stock was fed newly hatched brine shrimp (Artemia nauplii) in the morning and flake food (Trea, Germany) in the afternoon. Eggs were collected daily from the females at less than $2 \mathrm{~h}$ after fertilization. Filaments attaching adjacent eggs were removed by using a sucker to pull the individual eggs from the rest of the clusters. Eggs were checked using a dissecting microscope. Eggs with the migration of oil globules to the vegetal pole were deemed to be fertilized (Kirchen and West, 1976). Eggs were disinfected by placing them in a $0.9 \%$ solution of hydrogen peroxide for $10 \mathrm{~min}$ (Marking et al., 1994) and then placed in embryo rearing medium (ERM) (Kirchen and West, 1976) until initiation of exposure.

\subsection{Experimental design}

\subsubsection{6-h larval mortality experiment}

Medaka larvae were exposed to 0 (blank), 20, 30, 40,50 and $60 \%$ of RW and to 0 (blank), 60, 70, 80, 90 and $100 \%$ of effluents from SS, SS-UF, SS-UF-RO, SS-MF and SS-AC. In each vial, 10 newly hatched larvae and $100 \mathrm{ml}$ test solution were added. Three replicates were conducted for each concentration gradient and control. All the vials were stored in an incubator at $25^{\circ} \mathrm{C}$. Larvae were examined daily for mortality and were fed with newly hatched brine shrimp only once. The experiment was carried out in a static renewal assay procedure ( $24 \mathrm{~h}$ renewal).

\subsubsection{Short-time chronic exposure experiment}

2.3.2.1. Embryological phase. Exposure was initiated at $<4 \mathrm{~h}$ after fertilization. Medaka embryos were exposure to $6.25,12.5,25,50$ and $100 \%$ effluent concentrations. In each treatment, 100 embryos were randomly separated into five groups with 20 embryos in each test chamber (cylindrical glass cups with diameter of $9 \mathrm{~cm}$ and depth of $6 \mathrm{~cm}$ ). Each chamber then received $100 \mathrm{ml}$ test solution and was thereafter incubated at $25{ }^{\circ} \mathrm{C}$ under a $16: 8 \mathrm{~h}$ light:dark photoperiod. Five replicates were performed for each gradient and control. The developing embryos were observed under a stereoscopic microscope until all the living embryos had hatched. The test solution was renewed every second day until all the able embryos hatched. Any dead embryos were discarded as the assay 
progressed. Embryos cultured in embryos rare medium (ERM) were used as the control.

2.3.2.2. Larval phase. Newly hatched larvae and $500 \mathrm{ml}$ test solution were placed into another cup $(1000 \mathrm{ml})$ at $25^{\circ} \mathrm{C}$ under a $16: 8 \mathrm{~h}$ (light:dark) photoperiod. Each gradient and control had five replicates. All larvae were fed an adequate amount of newly hatched brine shrimp (A. nauplii) three times each day. Deformity, swim-up failure and mortality until 15 days post-hatch were observed and recorded. The test solution was renewed each day. Larvae cultured in ERM were used as the control.

\subsection{Endpoints}

The embryological and larval stages of medaka development have already been well documented (Iwamatsu, 1994). The morphology of the embryos was checked using a dissecting microscope and recorded with a digital camera. The numbers of live, lesion and dead embryos were recorded daily. After hatching, the number of live, deformed and dead larvae was monitored.

At 15-day post-hatching, all surviving larvae were sacrificed in $500 \mathrm{mg} / \mathrm{l} \mathrm{MS} 222$ buffer (Sigma, USA) and then the shape of the dorsal as well as anal fins and the color of external secondary sex characteristics were observed under a stereoscopic microscope. The fish were then blotted on filter paper, and their body weight and total length were measured.

\subsection{Data analysis}

All statistical analyses were performed using SPSS Base $11.5 \mathrm{~J}$ software (SPSS, Japan). To determine differences among treatment and control and different treatment groups, we conducted the following statistical analyses. Except for the data on sex ratios all the other data were checked for homogeneity of variances across treatments by Levene's test. When the assumptions were met, the data were subjected to one-way analysis of variance followed using the Dunnett's multiple comparison tests. When no homogeneity was observed in the data, the nonparametric Kruskal-Wallis test was used followed by the Mann-Whitney $U$-test with Bonferroni's adjustment. The data on sex ratios were assessed using the chi- squared analysis. Differences were considered to be significant at $P \leq 0.05$. LC50 values were calculated by probit transformation using the computer software SOFTTOX $^{\mathrm{TM}}$ distributed by WINDOWCHEM ${ }^{\mathrm{TM}}$ Fairfield, CA, USA.

\section{Results and discussions}

\subsection{Water quality parameters}

The $\mathrm{pH}$ of the effluents from various stages of treatment ranged between 7 and 8 except for the effluent from SS-UF-RO which had pH 6.48 (Table 1). The lower pH in SS-UF-RO could be related to lower TDS whereas the higher $\mathrm{pH}$ in effluent of SS-AC could be due to removal of metals ions (Dinesh and Kunwar, 2002). In all treatments except that for RW, dissolved oxygen (DO) was increased to levels of 5.8-6.4 mg/l to satisfy the requirement for fish test (USEPA, 2002). There were no significant differences in water quality parameters among treatments.

\subsection{Acute toxicity}

For newly hatched medaka larvae exposed, 96-h LC50s for effluents from RW, SS, SS-UF and SS-MF were $33.7,62.9,60$ and $64.4 \%$, respectively (Table 2). On contact, the effluents from SS-UF-RO and SS-AC had not manifested acute toxicity on newly hatched medaka larvae at 96-h exposure. Based on the data of 48-h LC50 (Table 2), SS-UF and SS-MF even concentrated the toxicants in comparison with that for SS.

Table 1

$\mathrm{pH}$, TDS, CON and DO of water samples from various stages of treatment and controls ${ }^{\mathrm{a}}$

\begin{tabular}{lllcl}
\hline Treatment & $\mathrm{pH}$ & $\mathrm{TDS}(\mathrm{mg} / \mathrm{l})$ & $\mathrm{CON}(\mu \mathrm{S} / \mathrm{l})$ & $\mathrm{DO}(\mathrm{mg} / \mathrm{l})$ \\
\hline RW & 7.65 & 488 & 994 & 0.7 \\
SS & 7.87 & 427 & 873 & 5.8 \\
SS-UF & 7.48 & 408 & 838 & 6.4 \\
SS-MF & 7.47 & 410 & 834 & 6.1 \\
SS-MF-RO & 6.48 & 26 & 54.1 & 6.2 \\
SS-AC & 7.91 & 401 & 821 & 6.2 \\
control & 6.97 & 545 & 1107 & 5.8 \\
\hline
\end{tabular}

${ }^{\text {a }}$ DO, TDS and CON represent dissolve oxygen, total dissolve solid and conductivity, respectively. Data are the mean of five replicates. 
Table 2

96-h LC50 of the effluents from RS and various treatment progresses on newly hatch medaka larvae

\begin{tabular}{llll}
\hline \multirow{2}{*}{$\begin{array}{l}\text { Source of effluent } \\
\text { samples }\end{array}$} & \multicolumn{3}{l}{ LC50 (\% effluents concentrations) } \\
\cline { 2 - 4 } & $24(\mathrm{~h})$ & $48(\mathrm{~h})$ & $96(\mathrm{~h})$ \\
\hline RW & 55.4 & 39.4 & 33.7 \\
SS & $\mathrm{nd}^{\mathrm{a}}$ & $\mathrm{nd}$ & 62.9 \\
SS-UF & nd & 81.5 & 60 \\
SS-MF & nd & 83.8 & 64.4 \\
SS-AC & nd & nd & nd \\
SS-UF-RO & nd & nd & nd \\
\hline
\end{tabular}

RW, SS, SS-UF, SS-MF, SS-AC, SS-UF-RO showed outflow of raw sewage water, secondary treatment, ultrafiltration treatment after SS, micro-filtration treatment after SS, active carbon column adsorption after SS, as well as reverse osmosis treatment after SS-UF (SS-UFRO), separately.

${ }^{\text {a }}$ No acute toxicity detected.

The results showed that secondary treatment could remove most of the toxicants in raw water and that SSUF-RO and SS-AC perform better compare to all the other technologies tested. Based on chemical measurements, the AC process has been shown to more efficiently remove organic compounds and heavy metals from waters (Bansode et al., 2003; Dinesh and Kunwar, 2002). Similarly, recent research has shown that UF-RO also effectively removed trace toxicants (Brehant et al., 2002). These findings are better confirmed based on the early life stage toxicity test performed in the present study. Mavrov et al. (1998) reported that both UF and MF could remove microorganisms and turbidity from the water. However, these technologies should not be recommended for case where the secondary effluent is intended for reuse because they did not effectively removed acute toxicity and TDS when used in combination with secondary treatment (Table 1 ).

\subsection{Embryo development phase effect}

\subsubsection{Embryo lesions}

Abnormalities of embryos in all effluents and controls were observed after day 4 (Fig. 1). Most embryos were normal in the controls, the effluents from SS-UF-RO and in SS-AC effluents. In previous works, medaka embryos exposed to 2,3,7,8-terachlorodibenzo-p-dioxin (TCDD, Wisk and Cooper, 1990), bisphenol A (BPA, Stephanie et al., 2001) and a polychlorinated naphthalene (PCN) mixture (Halowax
1014, Villalobos et al., 2000a) exhibited lesions after day 4 or 5 , or the time of formation of the liver (Villalobos et al., 2000b). The lesions would, to some extent, affect hatching success of embryos and the growth and survival of the larvae (Kjorsvik et al., 1990).

Almost all embryos in $100 \%$ RW effluent were dead at day 3 and $100 \%$ of the few embryos that still existed in this effluents had lesions by 7 days. The lesion rates of embryos exposed to RW were significantly different $(P<0.05)$ from that in the effluents of other types of treatment and from the controls (Fig. 2). The lesion rates of embryos exposed to high concentrations SS, SS-UF, SS-MF effluents were slightly different $(P<0.05)$ with controls (Fig. 2). However, the lesion rates of embryos in SS-UF-RO and SS-AC effluents were not significantly different from the controls. These results further showed that SS-UF-RO and SS-AC technologies had a good performance on removal of toxicants.

\subsubsection{Time to hatch and hatching rates}

Time for embryos to hatch after exposing them to effluents from all the various stage of treatment was not significantly different from the controls (data not shown). However, no embryos hatched in the $100 \%$ RW effluent. At 50\% RW effluent, hatching of embryos was delayed, but the delay was not statistically significant. There were not significant differences in the hatching time between the controls and the low RW effluent concentrations $(25,12.5$ and $6.75 \%$ ) (data not shown).

Hatching rates are an index that directly determines the quality of the larvae and affect the survival of a species. Hatching rates were sensitive to changes of the environment (Dettlaff et al., 1993). Hatching success of embryos exposed to $50 \%$ RW effluent was significantly less than in the controls and the other treatment $(P<0.05)$. The hatching rate of embryos exposed to 25 and $12.5 \% \mathrm{RW}$ effluent were also statistically less than in the controls $(P<0.05)$ (Fig. 3). In previous studies, a reduction of hatching success, induced by an exposure to single chemicals, has been reported in a number of types of fish, such as in medaka when exposed to 4-nolyphenol (NP, Hirofumi et al., 2001) and fathead minnow when exposed to ethinylestradiol (EE2, Reinhard et al., 2001). Reduction of hatching success was also 

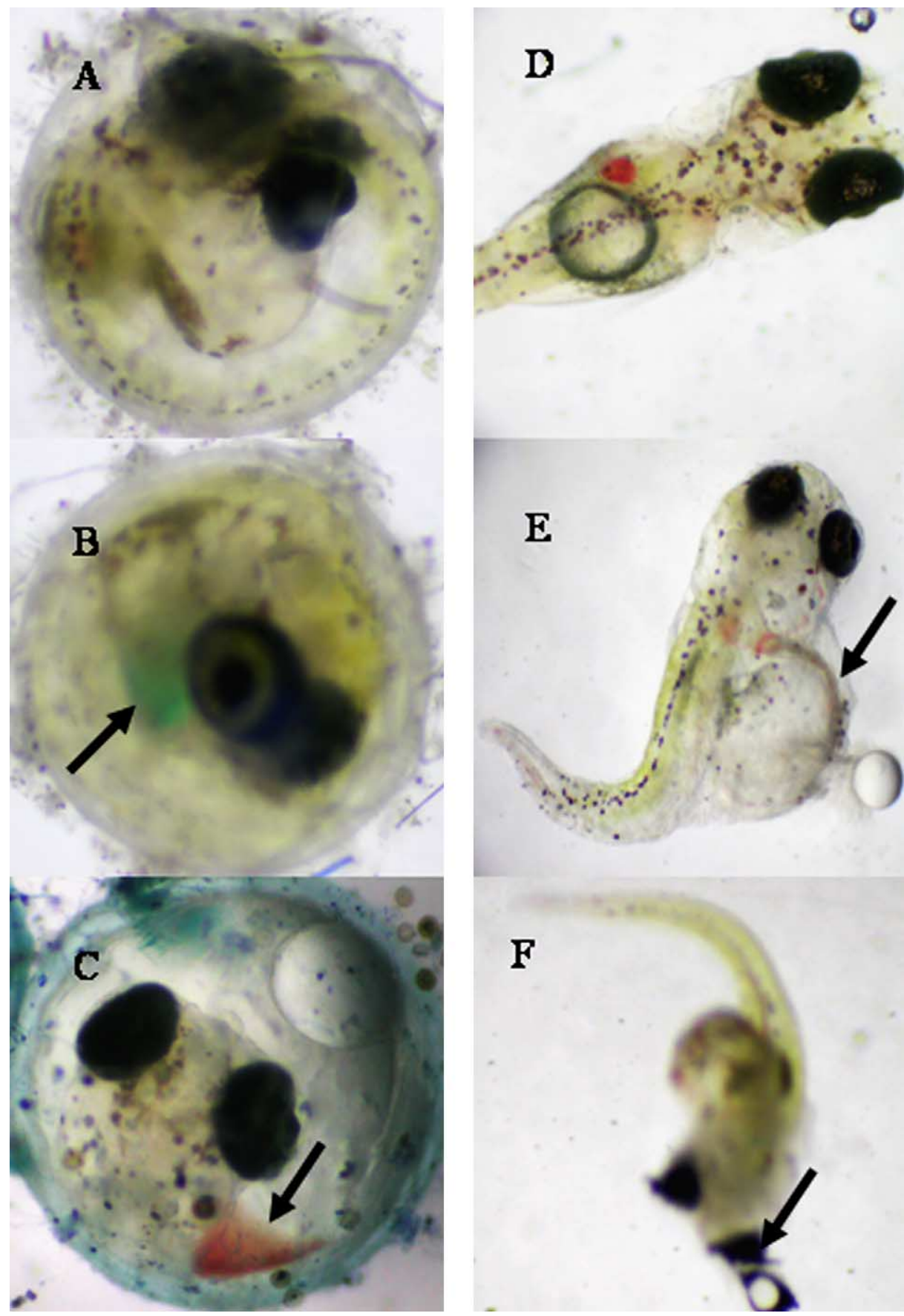

Fig. 1. Different characters of lesions embryos and newly hatching deformity larvae: (A) normal embryos; (B) lesion embryo, arrow shows pericardial edema; (C) lesion embryo, arrow shows hemorrhage; (D) normal larvae; (E) deformity larvae, arrow shows swollen abdomen; (F) deformity larvae, arrow shows distortion of eyes. 


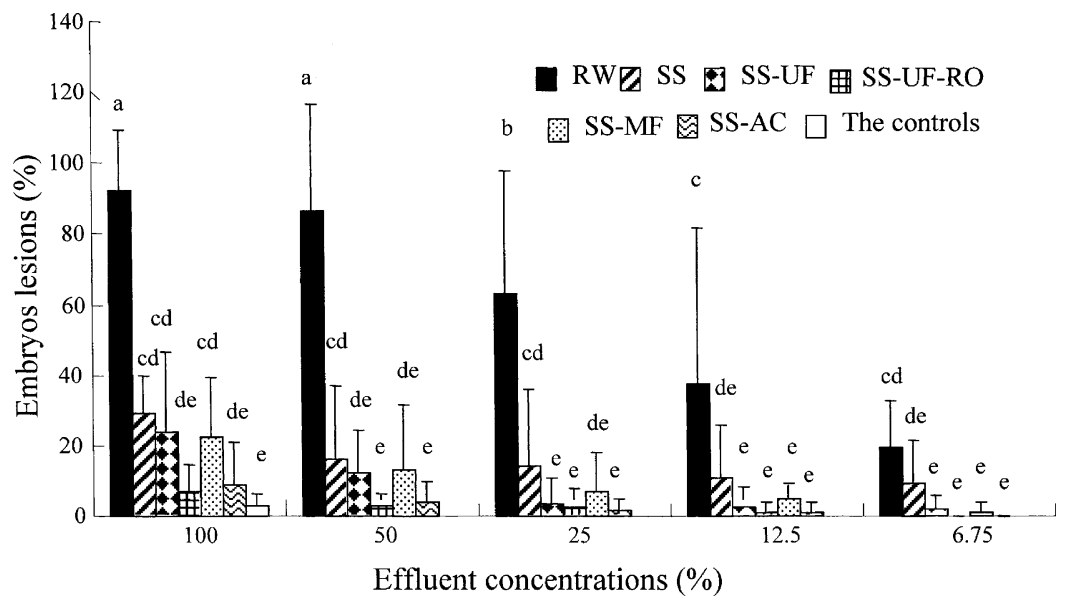

Fig. 2. Embryo lesions of medaka embryos exposed to different diluted effluents from raw sewage, the controls and various stages of treatment. Error bars are standard deviations. Columns with the same letter above them are not significantly different $(P<0.05)$.

observed in polluted environment, such as M74 pollution (environmentally related disease found in 1974) in Baltic salmon and the equivalent EMS syndrome in salmonids in North American Great lakes (AFS, 1996).

Hatching rates of embryos exposed to $100 \%$ SS effluents were very low and significantly less than in the controls $(P<0.05)$ (Fig. 3). Although hatching rates of embryos in $100 \%$ SS-MF and SS-UF effluents were different from those of the controls
$(P<0.05)$ (Fig. 3), they were not different from those of embryos exposed to $100 \%$ SS effluents. Hatching success of embryos exposed to $100 \%$ SSAC effluent concentrations were significantly less than in the controls $(P<0.05)$ (Fig. 3). However, hatching success of embryos in SS-UF-RO effluents did not significantly differ from the controls. The results showed that effluents from SS-UF-RO posed a less hazardous risk on receiving aquatic biology.

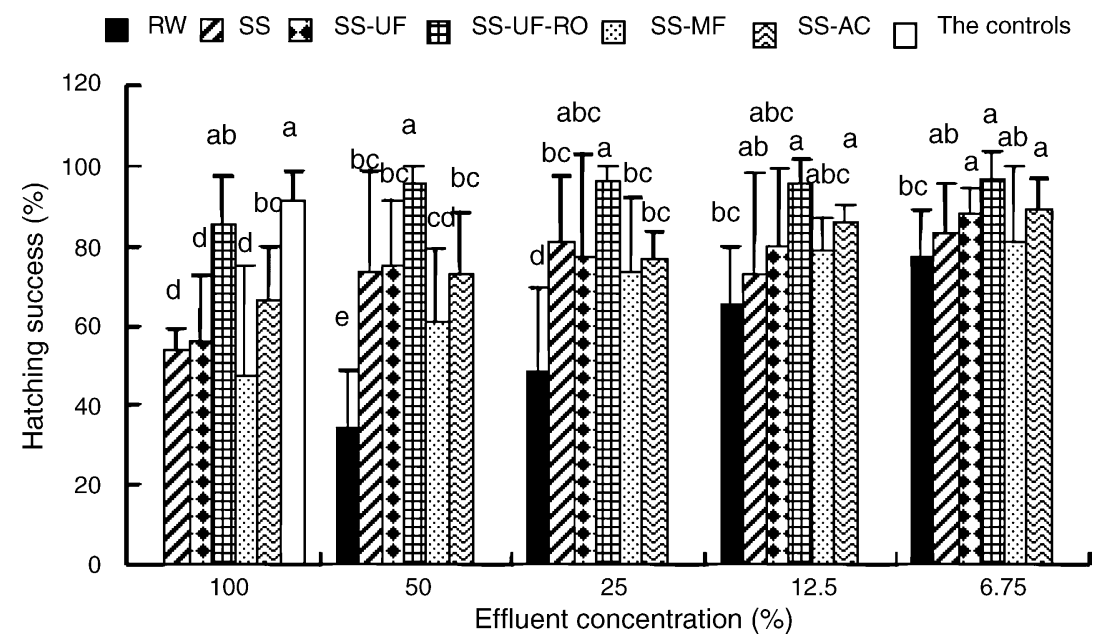

Fig. 3. Hatching success of medaka embryos exposed to different diluted effluents from raw sewage, the controls and various stages of treatment. Error bars are standard deviations. Columns with the same letter above them are not significantly different $(P<0.05)$. 


\subsection{Larval phase effect}

\subsubsection{Deformities of newly hatching larvae}

Deformities of newly hatching larvae in water from various treatment technologies were observed (Fig. 1). The tail of some larvae curled and distorted whereas the abdomen swelled. In a previous study, deformities were observed in rainbow trout (Oncorhynchus mykiss) and zebrafish (Danio rerio) when exposed to 7-isopropyl-1-methylphenanthrene at concentrations of 32-320 $\mu \mathrm{g} / \mathrm{L}$ (Sonya et al., 1998). In our recent work, there was blue sac when medaka embryos were exposed to a banknote printing plant (BPP) effluent (data to be published).

Deformity rates of larvae at 50\% RW effluents were significantly higher $(P<0.05)$ than in the controls and other treatments (Fig. 4). In 25\% RW and 100, 50, 25\% SS effluent, they were significantly different $(P<0.05)$ from the controls (Fig. 4). Though deformity rates of larvae in $100 \%$ SS-UF and SSMF effluent were lower than that in $100 \%$ SS effluent, they were significantly higher $(P<0.05)$ than in the controls (Fig. 4). The other treatments had no significantly different deformity rates from the controls although deformity rates of larvae exposed to $100 \%$ SS-UF-RO effluent were even lower than those of the controls. Based on deformities rates, the SS-UF-RO and SS-AC technologies performed quite well in removing toxicants.

\subsubsection{Swim-up failure}

Swim-up failure is the consequence of chronic intoxication and an index that directly determined the quality of the species. No larvae at $100 \%$ SS, SS-UF, SS-MF and 50\% RW effluents survived. They were significantly different with controls and other treatments $(P<0.05)$ (Fig. 5). With 50\% SS, SS-UF, SSMF effluents, a significant number $(P<0.05)$ of the larvae failed to swim up (Fig. 5). There were also significant differences in the number of the larvae that failed to swim-up in the 50\% SS, SS-UF, SS-MF effluents. The swim-up failures of larvae in high concentration SS-UF-RO effluents were significantly higher $(P<0.05)$ than in the controls (Fig. 5) possibly due to the removal of large mounts of TDS. Similarly, Charlon and Bergot (1991) reported that absence of some necessary salts would cause swim-up failure of the newly hatching larvae. However, the larvae in SSAC effluents had no significantly different swim-up failure with the controls. The results suggested that SS-AC effluents supplied a good environment on swim-up of the fish.

\subsubsection{Mortality rates after swim-up}

Mortality rates after swim-up in effluents from RW and various treatment techniques were not significantly different with the controls. All mortality rates were less than $10 \%$ (data not showed) indicating that mortality rate after swim-up was not a sensitive

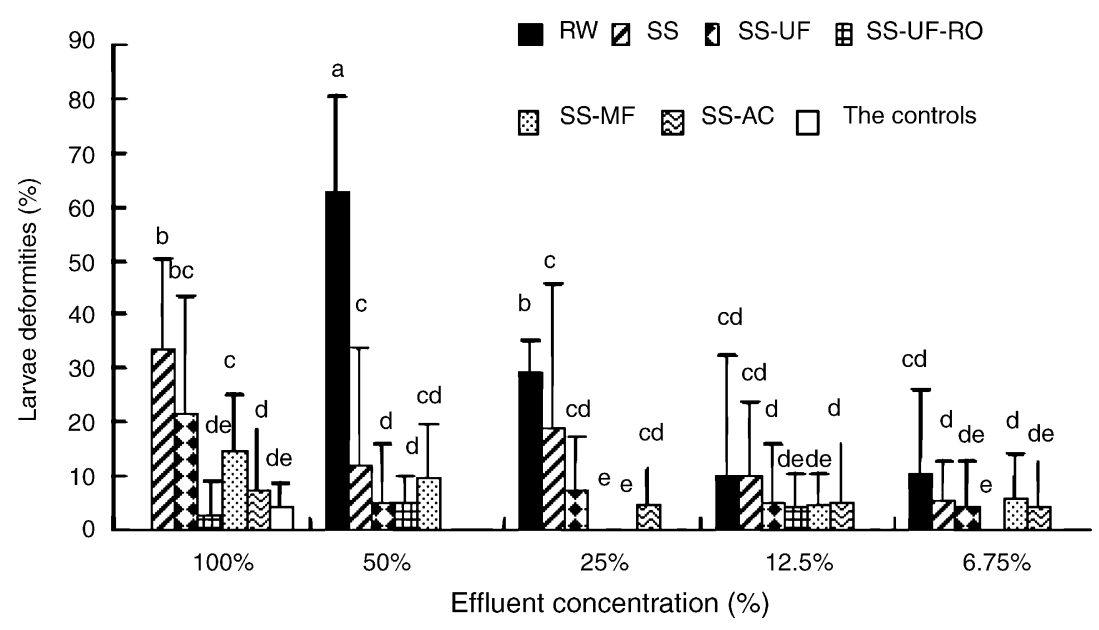

Fig. 4. Deformities of medaka larvae exposed to different diluted effluents from raw sewage, the controls and various stages of treatment. Error bars are standard deviations. Columns with the same letter above them are not significantly different $(P<0.05)$. 


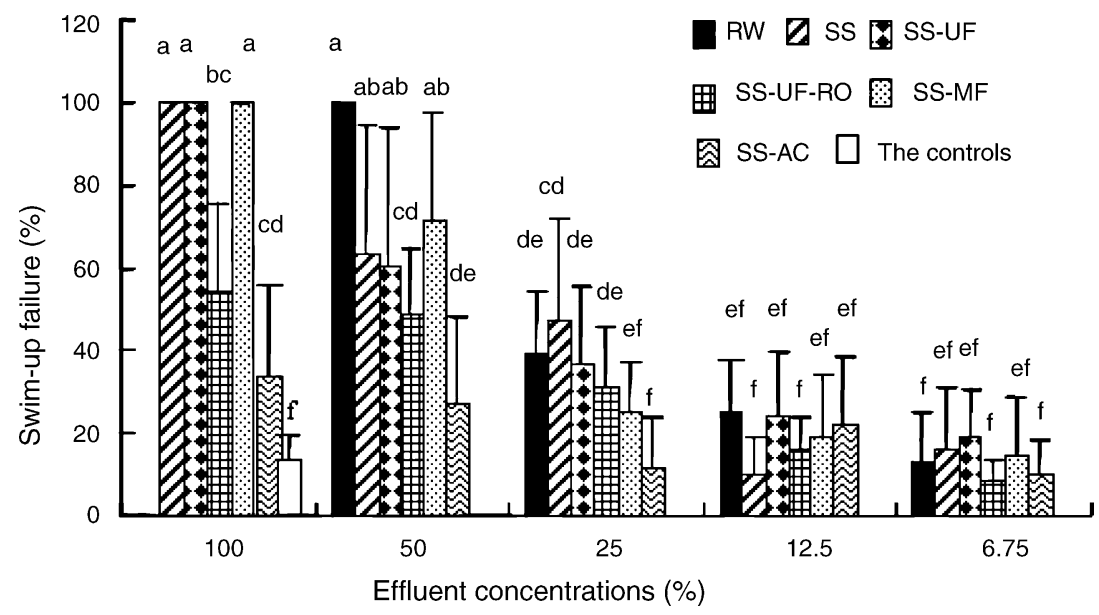

Fig. 5. Swim-up failure of medaka larvae exposed to different diluted effluents from raw sewage, the controls and various stages of treatment. Error bars are standard deviations. Columns with the same letter above them are not significantly different $(P<0.05)$.

indicator for assessing early life stage exposure to assessment the effluent from various treatment technologies.

\subsubsection{Larvae growth}

Larvae growth was always an index that determined the quality of the water. In this experiment, we measured the total body length (TBL) and wet body weight (WBW) of the larvae at 15 days after hatching.
The results showed that TBL and WBW of medaka larvae grown in the effluents from SS, SS-UF, SS-MF, SS-AC had not significant difference from the controls. Similarly, TBL and WBW of the larvae that were exposed to $25 \% \mathrm{RW}$ did not significantly differ with the controls (Table 3). TBL and WBW of larvae grown in 100, 50, 25\% SS-UF-RO treatment technologies was significantly less than the controls and the other treatments except $25 \mathrm{RW}(P<0.05)$

Table 3

Total body length (TBL), wet body weight (WBW) and sex ratio( $(+\overbrace{}^{\wedge})$ of larvae at 15-day post-hatching in different diluted effluents from raw sewage, controls and various stages of treatment progresses

\begin{tabular}{|c|c|c|c|c|c|c|}
\hline \multirow[t]{2}{*}{ Treatment } & \multirow[t]{2}{*}{ Concentrations $(\%)$} & \multicolumn{2}{|c|}{ Total body length (mm) } & \multicolumn{2}{|c|}{ Wet body weight (mg) } & \multirow[t]{2}{*}{ Sex ratio $\left(\circ:{ }^{\prime}\right)$} \\
\hline & & Mean & S.E. & Mean & S.E. & \\
\hline RW & 25 & $15.9 \mathrm{a}$ & 2.4 & $38.2 \mathrm{a}$ & 15.6 & $20: 10^{* a}$ \\
\hline \multirow[t]{2}{*}{ SS } & 50 & $17.3 \mathrm{abc}$ & 1.6 & $58.4 \mathrm{e}$ & 19.5 & $18: 9^{*}$ \\
\hline & 25 & $17.3 \mathrm{abc}$ & 1.8 & $51.7 \mathrm{de}$ & 18.4 & $25: 19$ \\
\hline \multirow[t]{2}{*}{ SS-UF } & 50 & $17.2 \mathrm{abc}$ & 1.7 & $49.1 \mathrm{bcd}$ & 20.5 & $19: 10^{*}$ \\
\hline & 25 & $17.6 \mathrm{bc}$ & 2.9 & $49.6 \mathrm{bcd}$ & 24.7 & $25: 25$ \\
\hline \multirow[t]{3}{*}{ SS-UF-RO } & 100 & $15.3 \mathrm{a}$ & 1.5 & $39.3 \mathrm{a}$ & 11.8 & $20: 20$ \\
\hline & 50 & $15.1 \mathrm{a}$ & 1.5 & $37.2 \mathrm{a}$ & 11.3 & $24: 26$ \\
\hline & 25 & $15.4 \mathrm{ab}$ & 1.8 & 39.9 a & 11.6 & $31: 35$ \\
\hline \multirow[t]{2}{*}{ SS-MF } & 50 & $17.7 \mathrm{bc}$ & 1.1 & $49.8 \mathrm{bc}$ & 18.1 & $11: 6^{*}$ \\
\hline & 25 & $18.0 \mathrm{bc}$ & 0.9 & $50.6 \mathrm{~cd}$ & 16.6 & $30: 24$ \\
\hline \multirow[t]{3}{*}{ SS-AC } & 100 & $17.6 \mathrm{bc}$ & 1.1 & $49.9 \mathrm{bcd}$ & 8.3 & $30: 27$ \\
\hline & 50 & $17.8 \mathrm{bc}$ & 1.9 & $50.5 \mathrm{bcd}$ & 12.4 & $28: 26$ \\
\hline & 25 & $17.3 \mathrm{bc}$ & 1.4 & $52.5 \mathrm{~cd}$ & 12.8 & $36: 32$ \\
\hline Controls & 0 & $18.3 \mathrm{c}$ & 1.8 & $54.1 \mathrm{cde}$ & 14.2 & $40: 39$ \\
\hline
\end{tabular}

Data expressed as mean \pm S.E. of five replicates for each treatment. Within columns, treatment means followed by different letters are significantly different $(P \leq 0.05)$.

a Significantly different from the control: ${ }^{*} P<0.05$; the statistic methods was chi-squared analysis. 
(Table 3). Surprisingly, the $12.5 \%$ SS-UF-RO treatment also significantly reduced TBL and WBW in larvae compare to the controls $(P<0.05)$ possibly because this treatment technology removes many TDS. Removal of TDS may also get rid of some useful components (Table 1), causing a difficulty in assimilating nourishment, slowing down the growth of the fish. These results are in agreement with those of previous studies. For example, Nimrod and Benson (1998) reporting that exposed newly hatched medaka fry to $0.01-1.66 \mu \mathrm{g} / \mathrm{L}$ of E2 for 28 days followed by a post-dosing recover period of 28 days reduced the total body length and weight. In other studies, the decreasing of total body length and weight of zebrafish were observed after exposure to EE2 (Van et al., 2003), cadmium (Bresch, 1982) and TCDD (Elonen et al., 1998).

\subsection{Sex ratios}

The sex ratio was a good indicator of endocrine disruption in the fish. For example, an increasing ratio of males to females was found in many types of fish including medaka after exposure to estrogen (E2) (Scholz and Gutzeit, 2000), EE2 (Metcalfe et al., 2001) and 4-NP (Hirofumi et al., 2001). In the present study, the sex ratio of the larvae was alternated when exposed to $25 \%$ effluents from RW and 50\% effluents from SS, SS-UF and SS-MF (Table 3). Females were significantly $(P<0.05)$ more than males at higher concentrations of RW, SS, SS-UF and SS-MF displaying a feminization phenomenon. This was similar with the result of BPP effluents (Zha and Wang, 2005). However, the sex ratios in treatments with effluents from SS-AC and SS-UF-RO did not significantly differ from the controls. Both SS-AC and SS-UF-RO did not affect the sex ratio indicating that both techniques were quite well in removing of endocrine disruptors.

\section{Conclusions}

Present study suggested that both acute, chronic toxicities and endocrine disrupting could be observed for raw sewage and effluent from secondary treatment. Secondary treatment could remove part of toxicants from raw water. Among advanced treatment technol- ogies, micro-filtration and ultrafiltration do not manifest efficiencies regarding to the removal of trace toxicants and endocrine disruptors. Active carbon adsorption and the combination of ultrafiltration and reverse osmosis are the most effective ones in removal of most toxicants. In addition, the proposed procedure based on the early life stage toxicity of Japanese medaka is valuable to screen acute and chronic toxicities and endocrine disrupting in effluents from different advanced treatment technologies for wastewater reclamation.

\section{Acknowledgements}

This work was supported by the Chinese Academy of Sciences (KZCX2-414), China Natural Science Foundation (20337020) and project NKBRSF2003 CB415005.

\section{References}

AFS, 1996. Early mortality syndrome: reproductive disruptions in fish in the Great Lakes, New York, Finger Lakes, and the Baltic Region. Symposium as Part of the 126th Annual Meeting of the American Fisheries Society, August 26-29, Dearborn, MI, USA. Abstract volume, $172 \mathrm{pp}$.

Anders, S., Allard, A.S., Mats, E.K., 2003. Removal of estrogenicity in Swedish municipal sewage treatment plants. Water Res. 37, 4433-4443.

Bansode, R.R., Losso, J.N., Marshall, W.E., Rao, R.M., Portier, R.J., 2003. Adsorption of volatile organic compounds by pecan shelland almond shell-based granular activated carbons. Bioresource Technol. 90, 175-184.

Brehant, A., Bonnelye, V., Perez, M., 2002. Comparison of MF/UF pretreatment with conventional filtration prior to RO membranes for surface seawater desalination. Desalination 144, 353-360.

Bresch, H., 1982. Investigation of the long-term action of xenobiotics on fish with special regard to reproduction. Ecotox. Environ. Saf. 6, 102-112.

Chaler, R., Simoneit, B.R.T., Grimalt, J.O., 2001. Bile acids and sterols in urban sewage treatment plants. J. Chromatogr. A 927, 155-160.

Charlon, N., Bergot, P., 1991. Alimentation artificielle des larvaes de I'esturgron siberien (Acipenser baeriBrandt). In: Williot, P. (Ed.), Proceedings of the First International Symposium on Sturgeon, CEMAGREF, Bordeaux, France, pp. 405-415.

Chunxia, W., Yi, W., Kiefer, F., Zijian, W., Kettrup, A., 2003. Ecotoxicological and chemical characterization of selected treatment progress effluents of municipal sewage plant. Ecotox. Environ. Saf. 56 (2), 211-217. 
Clint, M.P., David, M.J., 2003. Treated municipal sewage discharge affects multiple levels of biological organization in fish. Ecotox. Environ. Saf. 54, 199-206.

Dettlaff, T.A., Ginsburg, A.S., Schmalhausen, O.I., 1993. Sturgeon Fishes: Developmental Biology and Aquaculture. SpringerVerlag, Berlin, p. 300.

Dinesh, M., Kunwar, P.S., 2002. Single- and multi-component adsorption of cadmium and zinc using activated carbon derived from bagasse an agricultural waste. Water Res. 36, 2304-2318.

Elonen, G.E., Spehar, R.L., Holcombe, G.W., Johoson, R.D., Fernandez, J.D., Erickson, R.J., Tietge, J.E., Cook, P.M., 1998. Comparative toxicity of 2,3,7,8,-tetrachlorodibenzo- $p$ dioxin to seven freshwater fish species during early life-stage and development. Environ. Toxicol. Chem. 17, 472-483.

Fuerchker, M., Scharf, S., Pichler, W., Ertl, T., Haberl, R., 2001. Sources and behaviour of bismuth active substances (BiAS) in a municipal sewage treatment plant. Sci. Total Environ. 277, 95100.

Glucina, K., Alvarez, A., Laine, J.M., 2000. Assessment of an integrated membrane system for surface water treatment. Desalination 132, 73-82.

Heuvel, M.R., Ellis, R.J., Tremblay, L.A., Stuthridge, T.R., 2002. Exposure of reproductively maturing rainbow trout to a New Zealand pulp and paper mill effluent. Ecotox. Environ. Saf. 51, 65-75.

Hirofumi, Y., Masanori, S., Masanobu, M., Yuji, O., Hiroshi, T., Tsuneo, H., Kunio, K., 2001. Life-cycle toxicity of 4-nonylphenol to medaka (Oryzias latipes). Environ. Toxicol. Chem. 20, 2552-2560.

Islinger, M., Yuan, H., Voelkl, A., Braunbeck, T., 2002. Measurement of vitellogenin gene expression by RT-PCR as a tool to identify endocrine disruption in Japanese medaka (Oryzias latipes). Biomakers 7, 80-93.

Iwamatsu, T., 1994. Stages of normal development in the medaka (Oryzias latipes). Zool. Sci. 11, 825-839.

Johnson, L.L.C., Asillas, E., Collier, T.K., McCain, B.B., Varanasi, U., 1988. Contaminant effects on ovarian development in English sole (Parophrys vetulus) from Puget Sound, Washington. Can. J. Fish. Aquat. Sci. 45, 2133-2143.

Julia, R., Todorov, A.A., Elskus, D.S., Ferguson, P.L., Brownawell, B.J., McElroy, A.E., 2002. Estrogenic responses of larval sunshine bass (Morone saxtilis $\times$ M. chrysops) exposed to New York City sewage effluent. Mar. Environ. Res. 54, 691-695.

Kirchen, R.V., West, W.R., 1976. The Japanese Medaka Care and Development. Carolina Biological Supply Company, Burlington, NC, pp. 1-58.

Kjorsvik, E., Mangor-Jense, A., Holmefjord, I., 1990. Egg quality in fishes. Adv. Mar. Biol. 26, 71-113.

Lang, T., Damm, U., Dethlefsen, V., 1995. Changes in the sex ratio of North Sea dab (Limanda limanda) in the period 1981-1995. International Council for the Exploration of the Sea, Conseil International pour I'Exploration de la Mar 1995 Documents G:25, Aalborg, Denmark.

Madaeni, S.S., Fane, A.G., Grohmann, G.S., 1995. Virus removal from water and wastewater using membranes. J. Membr. Sci. $102,65-75$.
Marking, L.L., Rach, J.J., Schreir, T.M., 1994. Evaluation of antifungal agents for fish culture. Prog. Fish. Cult. 56, 224-231.

Mavrov, V., Chmiel, H., Kluth, J., Meier, J., Heinrich, F., Ames, P., Backes, K., Usner, P., 1998. Comparative study of different MF and UF membranes for drinking water production. Desalination 117, 189-196.

McArdle, M.E., Elskus, A., McElroy, A., Larsen, B., Benson, W., Schlenk, D., 2000. Estrogenic and CYP1A response of mummichogs and sunshine bass to sewage effluent. Mar. Environ. Res. 50, 175-179.

Metcalfe, C.D., Metcalfe, T.L., Kiparissis, Y., Brenda, G., Khan, C., Hughes, R.J., Croley, T.R., March, R., Potter, T., 2001. Estrogenic potency of chemicals detected in sewage treatment plant effluents as determined by in vivo assays with Japanese medaka (Oryzias latipes). Environ. Toxicol. Chem. 20, 297-308.

Montsrrat, S., Cinta, P., Damia, B., 2001. Analysis of the estrogenic activity of sewage treatment works and receiving waters using vitellogenin induction in fish as a biomarker. Trends Anal. Chem. 20, 518-525.

Mousa, S.M., Jamal, J., Maria, D., Afonsob, 2003. Desalination of brackish water by nanofiltration and reverse osmosis. Desalination $157,167$.

Nimrod, A.C., Benson, W.H., 1998. Reproduction and development of Japanese medaka following an early life stage exposure to xenoestrogens. Aquat. Toxicol. 44, 141-156.

Petersen, G.I., Gerup, J., Nilsson, L., Larsen, J.R., Schneider, R., 1997. Body burdens of lipophilic xenobiotics and reproductive success in Baltic cod (Gadus morhua L.). International Council for the Exploration of the Sea, Conseil International pour I'Exploration de la Mar1997 Documents U: 10, Baltimore, MD, USA.

Reinhard, L., Thomas, H.H., Charlotte, P.C., Fred, S., Hermann, S., Peter, H., Grace, H.P., John, P.S., 2001. Effects of the synthetic estrogen 17a-ethinylestrdiol on the life-cycle of the fathead minnow (Pimephales promelas). Environ. Toxicol. Chem. 20, 1216-1227.

Scholz, S., Gutzeit, H.O., 2000. 17-Alpha-ethinylestradiol affects reproduction, sexual differentiation and aromatase gene expression of the medaka (Oryzias latipes). Aquat. Toxicol. 50, 363373.

Sonya, B.M., Kirsten, Q., Peter, V.H., 1998. Toxicity of retene to early life stages of two freshwater fish species. Environ. Toxicol. Chem. 17, 2070-2077.

Stephanie, D.P., Villalobos, S.A., Kannan, K., John, P.C., 2001. Morphological effects of bisphenol-A on the early life stages of medaka (Oryzias latipes). Chemosphere 45, 535-541.

Trevizo, C., Nirmalak, H.N., 1999. Prediction of microbial toxicity of industrial organic chemicals. Water Sci. Technol. 39, 63-69.

USEPA, 2002. Short-time methods for estimating the chronic toxicity of effluent and receiving water to freshwater organism, 4th ed. U.S. Environmental Protection Agency Office of Water, NW Washington, DC, pp. 1-135.

Van, D.B., Verheyen, R., Witters, H., 2003. Effects of 17a-ethinylestradiol in partial life-cycle test with zebrafish (Danio rerio): effects on growth, gonads and female reproductive success. Sci. Total Environ. 309, 127-137. 
Villalobos, S.A., Hamm, J.T., The, S.J., Hinton, D.E., 2000a. Thiobencarb-induced embryo toxicity in medaka: stage-specific toxicity and the protective role of chorion. Aquat. Toxicol. 48, 309-326.

Villalobos, S.A., Papoulias, D.M., Meadows, J., Blankenship, A.L., Pastva, S.D., Kannan, K., Tillitt, D.E., Giesy, J.P., 2000b. Toxic responses of medaka strain to polychlorinated naphthalene mixtures after embryonic exposure by in ovo-nanoinjection: a partial life cycle assessment. Environ. Toxicol. Chem. 19, 432-440.
Wisk, J.D., Cooper, K.R., 1990. The stage specific toxicity of 2,3,7,8-tetrachlorodibenzo- $p$-dioxin in embryos of the Japanese medaka (Oryzias latipes). Environ. Toxicol. Chem. 9, 11591169.

Zha, J.M., Wang, Z.J., 2005. Acute and early life stage toxicity of industrial effluent on Japanese medaka (Oryzias latipes). Sci. To. Environ., in press. 